\title{
Prevention and treatment of cardiovascular disease in Ethiopia: a cost-effectiveness analysis
}

Mieraf Taddesse Tolla ${ }^{1 *}$, Ole Frithjof Norheim', Solomon Tessema Memirie', Senbeta Guteta Abdisa², Awel Ababulgu ${ }^{3}$, Degu Jerene ${ }^{4}$, Melanie Bertram ${ }^{5}$, Kirsten Strand $^{1}$, Stéphane Verguet ${ }^{6}$ and Kjell Arne Johansson ${ }^{1}$

\begin{abstract}
Background: The coverage of prevention and treatment strategies for ischemic heart disease and stroke is very low in Ethiopia. In view of Ethiopia's meager healthcare budget, it is important to identify the most cost-effective interventions for further scale-up. This paper's objective is to assess cost-effectiveness of prevention and treatment of ischemic heart disease (IHD) and stroke in an Ethiopian setting.

Methods: Fifteen single interventions and sixteen intervention packages were assessed from a healthcare provider perspective. The World Health Organization's Choosing Interventions that are Cost-Effective model for cardiovascular disease was updated with available country-specific inputs, including demography, mortality and price of traded and non-traded goods. Costs and health benefits were discounted at $3 \%$ per year. Incremental cost-effectiveness ratios are reported in US\$ per disability adjusted life year (DALY) averted. Sensitivity analysis was undertaken to assess robustness of our results.

Results: Combination drug treatment for individuals having $>35 \%$ absolute risk of a CVD event in the next 10 years is the most cost-effective intervention. This intervention costs US\$67 per DALY averted and about US\$7 million annually. Treatment of acute myocardial infarction (AMI) (costing US\$1000-US\$7530 per DALY averted) and secondary prevention of IHD and stroke (costing US\$1060-US\$10,340 per DALY averted) become more efficient when delivered in integrated packages. At an annual willingness-to-pay (WTP) level of about US\$3 million, a package consisting of aspirin, streptokinase, ACE-inhibitor and beta-blocker for AMI has the highest probability of being most cost-effective, whereas as WTP increases to > US\$7 million, combination drug treatment to individuals having $>35 \%$ absolute risk stands out as the most cost-effective strategy. Cost-effectiveness ratios were relatively more sensitive to halving the effectiveness estimates as compared with doubling the price of drugs and laboratory tests.

Conclusions: In Ethiopia, the escalating burden of CVD and its risk factors warrants timely action. We have demonstrated that selected CVD intervention packages could be scaled up at a modest budget increase. The level of willingness-to-pay has important implications for interventions' probability of being cost-effective. The study provides valuable evidence for setting priorities in an essential healthcare package for CVD in Ethiopia.
\end{abstract}

Keywords: Cost-effectiveness analysis, Cardiovascular disease, Ischemic heart disease, Stroke, Prevention, Treatment, Ethiopia

\footnotetext{
*Correspondence: maphy99@gmail.com

${ }^{1}$ Department of Global Public Health and Primary Health Care, University

of Bergen, Bergen, Norway

Full list of author information is available at the end of the article
} 


\section{Background}

Cardiovascular disease (CVD) is the leading cause of mortality globally. The Global Burden of Disease study estimated that about $32 \%$ of all deaths worldwide in 2013 were caused by CVD [1], with about $80 \%$ of these deaths occurring in low-and middle-income countries (LMIC) $[1,2]$.

Approximately $9 \%$ of all deaths in Ethiopia in 2012 were caused by CVD according to World Health Organization (WHO) estimates [3]. Small-scale local studies also reported an increasing burden from CVD and its risk factors, especially in urban settings in Ethiopia [4-15]. In a systematic review of studies conducted in Ethiopia between 1960 and 2011, CVD was reported to be among: (a) the prevalent causes of morbidity (range 4-24\%); (b) the main causes of hospital admission, especially among those older than 60 years (range 3-31\%); (c) the leading causes of medical intensive care unit admission (range 8.9-9.8 \%); and (d) among the major causes of mortality (range 6.5-24 \%) [15]. In Ethiopia's capital, Addis Ababa, an estimated $25 \%$ of all household deaths between 2006 and 2009 and $11 \%$ of all hospital deaths between 2002 and 2010 were attributed to CVD [7, 8]. Myocardial infarction, stroke and hypertensive heart disease accounted for about $75 \%$ of CVD deaths $[7,8]$. Modifiable risk factors like smoking, high cholesterol and high blood pressure explain the major share of the CVD burden $[16,17]$. The prevalence of hypertension in Ethiopia is estimated to range from 16 to $30 \%[5,6,13,14]$.

WHO recommends a combination of population-wide and individual-based prevention and basic treatment strategies for successful control of CVD [18, 19]. Current coverage of such interventions is low in Ethiopia. Only about a quarter of the patients diagnosed with CVD at two referral hospitals in Ethiopia were found to be on medication $[6,9]$.

Cognizant of the increasing burden from non-communicable diseases (NCDs), the Federal Ministry of Health of Ethiopia (FMOH) has launched a National Strategic Action Plan (NSAP) for Prevention and Control of NCDs, envisioning the scale-up of an essential package of NCD interventions targeting the four major NCDs, including CVD [20]. With Ethiopia's meager health spending of only about US\$ 21 per capita per year in 2011 [21], it is imperative to identify the most efficient strategies for further scale-up.

Cost-effectiveness analysis is a key tool to assist policy makers in selecting the most efficient strategy among competing alternatives. WHO-CHOICE (Choosing Interventions that are Cost-Effective) has undertaken costeffectiveness analysis of CVD interventions for the major regions in low- and middle-income countries [22-24]. Regional estimates have limited relevance to country-level decision making due to variation in key parameters. Parameters such as demography, epidemiology, costs and coverage of interventions vary widely across countries within the same regions, warranting the need for local evidence for better decision-making [23, 25-27]. To our knowledge there is no local evidence on cost-effectiveness of CVD interventions in Ethiopia. We therefore intend to fill this knowledge gap and inform the process of evidence-based resource allocation and priority setting for essential package for CVD interventions in Ethiopia.

This paper's objective is to undertake a cost-effectiveness analysis of primary prevention, acute treatment and secondary prevention of ischemic heart disease (IHD) and stroke in an Ethiopian setting.

\section{Methods}

We performed a generalized cost-effectiveness analysis of prevention and treatment strategies for CVD in an Ethiopian setting based on the WHO-CHOICE approach whereby, cost-effectiveness of each intervention is assessed compared with a 'no intervention' scenario [28]. Box 1 below depicts key socio-demographic and economic indicators for Ethiopia. A brief description of the interventions assessed, the modeling approach and the country-specific revisions are outlined below.

\section{Box 1 Key socio-demographic and economic parameters for Ethiopia, 2013/14}

\begin{tabular}{lll}
\hline Parameter & Level & Source \\
\hline Total population & 96.96 million & \\
Life expectancy at birth & 64 years & {$[29]$} \\
GDP per capita & US\$505 & \\
Currency exchange rate to US\$ & 17.7 & \\
PPP exchange rate & 7.08 & \\
Total health expenditure (annual) & US\$1.6 billion & \\
Per capita spending on health (annual) & US\$21 & [21] \\
Number of health facilities & & {$[30]$} \\
Hospital & 189 & \\
Health center & 3547 & \\
Health post & 16,251 & \\
\hline
\end{tabular}

\section{Interventions}

Fifteen single interventions and sixteen integrated intervention packages were assessed. Interventions target individuals without a history of established CVD but at risk of developing a CVD event; those with an acute CVD event; and those with a history of established CVD event. Interventions were selected based on the recommendations of WHO and local experts and scientific evidence of effectiveness. Full description of the interventions is outlined in Table 1. 


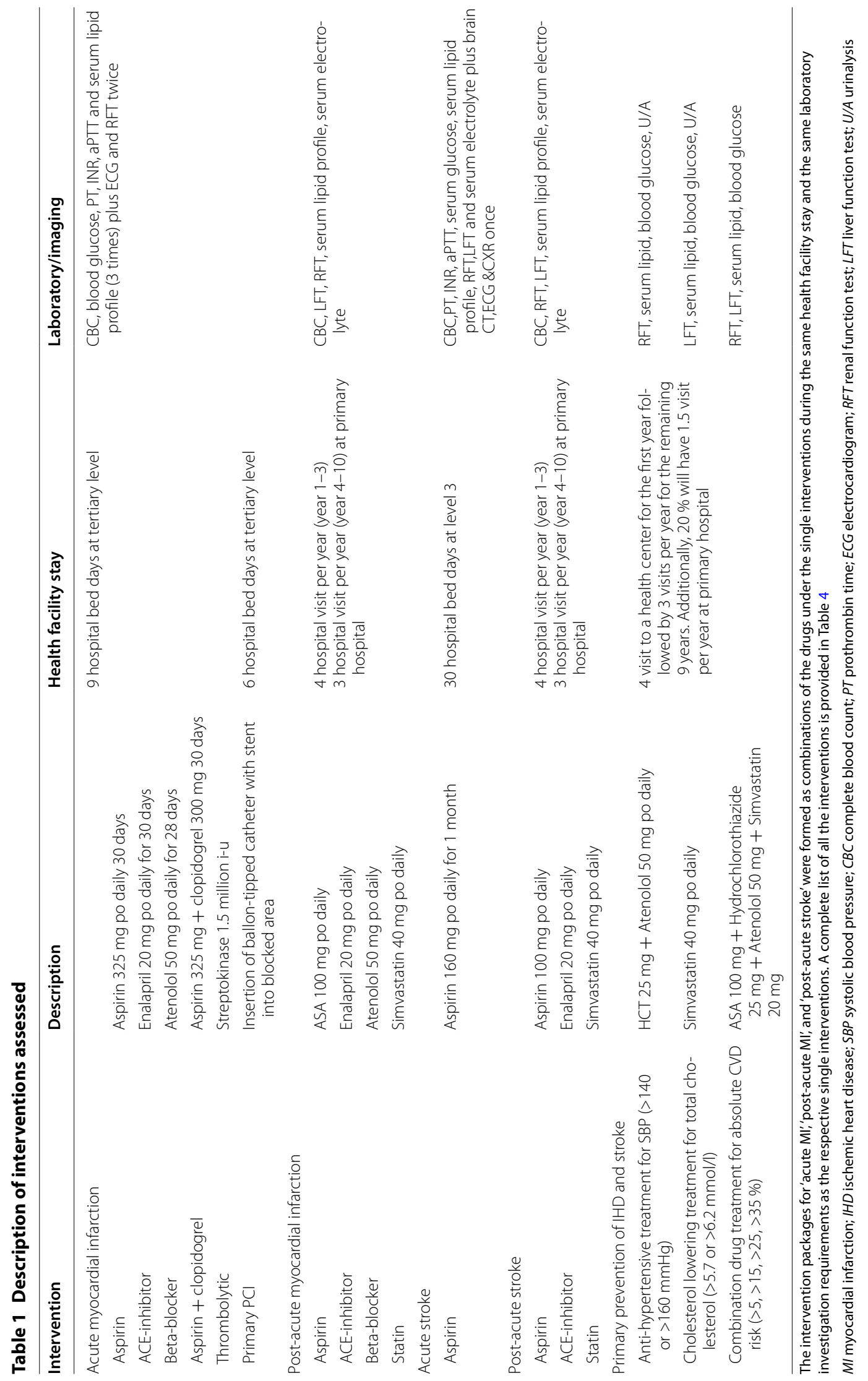


For primary prevention, individual-based drug regimens based on either the level of systolic blood pressure (SBP), the level of total serum cholesterol or the absolute risk of developing a CVD event over the next 10 years were assessed. Absolute risk is determined based on wellknown CVD risk factors (age, gender, SBP, smoking status, body mass index and total serum cholesterol level) $[18,19]$. The distribution of mean risk factor levels and smoking status in the population was stratified by age and gender based on the estimates from WHO's Comparative Risk Assessment project for East Africa region. Estimates of relative risk of developing a CVD event per unit increase in the level of risk factors was then applied to estimate the individual level relative risk of developing a CVD event which is then used to extrapolate the absolute risk of CVD event at population level $[19,31]$. The drug regimens are to be delivered on an outpatient basis at health centers and constitute: (a) a beta-blocker and a diuretic at SBP of $>140 \mathrm{mmHg}$ or $>160 \mathrm{mmHg}$; (b) statin treatment at serum cholesterol level of $>5.7 \mathrm{mmol} / \mathrm{l}$ or $>6.2 \mathrm{mmol} / \mathrm{l}$; and (c) a combination of aspirin, betablocker, diuretic and statin-based on the absolute risk of a CVD event for four thresholds $(>5,>15,>25$ or $>35 \%)$ respectively.

Interventions for acute myocardial infarction (AMI) constitute treatment with aspirin, streptokinase, clopidogrel, beta-blocker, ACE-inhibitor and surgical revascularization with percutaneous coronary intervention (PCI) on an inpatient basis. Aspirin is used for acute treatment of ischemic stroke; and beta-blocker, aspirin, ACEinhibitor and statin for secondary prevention of IHD and stroke. Interventions were first assessed individually; clinically relevant packages were then formed, building on the intervention with the lowest cost-effectiveness ratio.

Given the current low coverage of interventionsless than $5 \%$, based on experts' recommendationswe set modest target coverage of $20 \%$ for all of the interventions.

In the absence of local evidence, efficacy estimates were drawn from previous randomized controlled trials and meta-analyses performed elsewhere (Table 2) [32-46]. Efficacy estimates were adjusted by target coverage and patient adherence level [47-49].

\section{Modeling approach}

The WHO-CHOICE's CVD model for East Africa was used to undertake the analysis [50]. The model was updated with age and sex distribution, birth rate and background mortality rate for Ethiopia [51-53]. In the absence of national data on the current level of incidence, prevalence and mortality rates of IHD and stroke and the distribution of CVD risk factors, the analysis used respective estimates for the East Africa region [22, 23, 31, $50,52]$.

The effect of primary prevention interventions is modeled through their impact on the level of risk factors, which is used to recalculate the expected incidence rate for IHD and stroke after implementing the specific intervention. The new incidence rate is applied to estimate the reduction in mortality from the respective diseases. Interventions targeting AMI and acute stroke were modeled through the interventions' impact on 28-day case fatality rate, while secondary prevention interventions were modeled through their impact on post-acute case fatality rate. The effect of interventions was assumed to be the same across sub-groups.

We used PopMod, a multi-state population model, to estimate the health benefits in disability adjusted life years (DALYs) averted for the Ethiopian population resulting from changes in CVD risk due to specific interventions.

The population in the model is divided into age-sex categories of one-year intervals which are further stratified into four health states: (a) those having IHD; (b) those having stroke; (c) those having both; and (d) those without any of the conditions. Transition between states is dictated by the respective incidence, case fatality and mortality rates. Disability weights for the health states were drawn from the Global Burden of Disease Study 2010 [54]. PopMod traces the changes in population size in each age-sex category over a lifetime of 100 years by standard life table methods with and without specific interventions ('no intervention' scenario). Interventions are implemented for 10 years, after which the epidemiologic rates are taken back to the 'no intervention' level. Births and background mortality are taken into account $[31,55]$. The expected health benefits of the current coverage level of interventions are eliminated to create a hypothetical reference case of null scenario. The model provides removal of the benefits of current coverage of interventions, thereby allowing recalculation of the incidence, prevalence and case fatality rates for MI and stroke, assuming a scenario where the currently implemented interventions are stopped. The health benefits are reported in terms of DALYs averted, discounted at $3 \%$ per year without age weighting. The model has been used to undertake CEAs of various interventions in multiple settings [22]; and details have been published elsewhere $[23,24,55]$.

\section{Costs}

A healthcare provider perspective was used for analysis and hence only program costs, training costs and patientrelated costs to the provider were taken into account. Program costs constitute the cost of development and 
Table 2 Effectiveness assumption used in the model expressed in percentage reduction in the outcome of interest

\begin{tabular}{|c|c|c|c|}
\hline Intervention & Outcome affected & Efficacy in \% & Source \\
\hline \multicolumn{4}{|l|}{ Acute myocardial infarction } \\
\hline Aspirin & 28 day mortality & $22(15,29)$ & {$[31,36]$} \\
\hline ACE-inhibitor & 28 day mortality & $7(2,11)$ & {$[37,40]$} \\
\hline Beta-blocker & 28 day mortality & $13(2,23)$ & {$[37,40]$} \\
\hline Streptokinase & 28 day mortality & $26(17,31)$ & {$[36]$} \\
\hline ASA + clopidogrel & 28 day mortality & $32(17,47)$ & {$[31,34]$} \\
\hline $\mathrm{PCl}$ & 28 day mortality & $61(38,75)$ & {$[33,36,41]$} \\
\hline \multicolumn{4}{|l|}{ Post-acute myocardial infarction } \\
\hline Aspirin & Case fatality rate & $13(2,22)$ & {$[31,66]$} \\
\hline ACE-inhibitor & Case fatality rate & $23(14,30)$ & {$[42]$} \\
\hline Beta-blocker & Case fatality rate & $23(16,30)$ & {$[43]$} \\
\hline Statin & Case fatality rate & $19(15,24)$ & {$[44,67]$} \\
\hline \multicolumn{4}{|l|}{ Acute ischemic stroke } \\
\hline Aspirin & 28 day case fatality rate & $5(1,9)$ & {$[31]$} \\
\hline \multicolumn{4}{|l|}{ Post-acute stroke } \\
\hline Aspirin & Case fatality rate & $16(2,29)$ & {$[31]$} \\
\hline ACE-inhibitor & Case fatality rate & $16(12,30)$ & {$[45]$} \\
\hline Statin & Case fatality rate & $24(16,37)$ & {$[35]$} \\
\hline \multicolumn{4}{|l|}{ Primary prevention of IHD and stroke } \\
\hline $\begin{array}{l}\text { Anti-hypertensive treatment for systolic blood pres- } \\
\text { sure }(>140 \text { or }>160 \mathrm{mmHg})\end{array}$ & $\begin{array}{l}\text { Difference between actual systolic blood pressure } \\
\text { and } 115 \mathrm{mmHg}\end{array}$ & $33(31,44)$ & {$[40,46,68]$} \\
\hline $\begin{array}{l}\text { Cholesterol lowering treatment for total cholesterol } \\
(>5.7 \text { or }>6.2 \mathrm{mmol} / \mathrm{l})\end{array}$ & Serum level of total cholesterol & $20(17,23)$ & {$[27,44]$} \\
\hline $\begin{array}{l}\text { Combination drug treatment for absolute risk of } \\
\operatorname{CVD}(>5,>15,>25,>35 \%)\end{array}$ & $\begin{array}{l}\text { Effect on the level of systolic blood pressure plus } \\
\text { serum cholesterol plus aspirin }\end{array}$ & $(33)+(20)+(18)$ & {$[27,40,44,46,66,68]$} \\
\hline
\end{tabular}

administration of an intervention at national and subnational levels. This includes cost of administration and planning, media and communication, law enforcement, training, monitoring and evaluation. Patient-related costs consist only of direct medical costs incurred by the provider at the point of service delivery, including hospital bed days, outpatient visits, drugs and laboratory [28]. The analysis did not include direct non-medical costs such as transportation and indirect costs to patients and care givers such as lost productivity. The ingredients costing approach was employed whereby the quantities of resources required to deliver the interventions and respective unit prices were accounted for separately (Table 3). The quantities of resources used were largely determined based on WHO-CHOICE assumptions. We updated the prices of relevant laboratory tests and imaging using pricing from two public hospitals in Addis Ababa (Tikur Anbessa teaching hospital and Zewditu hospital). Salary scale of the health workforce was based on the FMOH of Ethiopia. Equipment and material prices were based on WHO price estimates for Ethiopia for the year 2012/13 [56] and drug prices were based on the lowest supplier prices for 2012, as noted in the International Drug Price Indicator Guide [57]. WHO-CHOICE's transport multiplier factor was applied to the drug prices. The total cost of an intervention was then calculated as the sum of the product of the quantities of resources with their respective unit prices. As recommended by WHOCHOICE costs were discounted at an annual rate of $3 \%$ [28] and reported in 2012 US\$.

\section{Cost-effectiveness}

All interventions were assessed compared to 'no intervention' scenario first, followed by incremental analysis between mutually exclusive interventions. Average costeffectiveness ratios (ACERs) were estimated dividing the incremental cost by incremental effects of each intervention compared with a 'no intervention' scenario. In order to assess the relative cost-effectiveness of mutually exclusive interventions, incremental cost-effectiveness ratios (ICERs) were estimated as the ratio of the incremental cost to incremental effects for moving from one intervention to the next more effective intervention, starting from the null scenario. Interventions that are more costly and less effective than their comparators or those having higher ICER than their more effective comparator are designated as dominated. ACERs and ICERs are reported in US\$ per DALY averted for the year 2012. 
Table 3 Price of intervention inputs applied in the model in Ethiopian birr 2012

\begin{tabular}{|c|c|c|c|}
\hline \multicolumn{3}{|c|}{ Unit price } & \multirow[t]{2}{*}{ Unit pric } \\
\hline \multicolumn{3}{|c|}{ Salary scale for human resource } & \\
\hline Medical specialist & 112,781 & $\begin{array}{l}\text { Director of public } \\
\text { health }\end{array}$ & 51,293 \\
\hline Medical officer & 76,723 & Public health specialist & 94,712 \\
\hline $\begin{array}{l}\text { Nursing director/ } \\
\text { manager }\end{array}$ & 64,728 & Public health assistant & 28,339 \\
\hline Registered nurse & 28,339 & $\begin{array}{l}\text { Health educator/ } \\
\text { trainer }\end{array}$ & 28,339 \\
\hline Health worker & 51,293 & Social/welfare worker & 28,339 \\
\hline \multicolumn{4}{|c|}{ Source: Federal Ministry of Health, Ethiopia 2012} \\
\hline \multicolumn{4}{|l|}{ Health facility visit/stay } \\
\hline Hospital bed days & & Health facility visit & \\
\hline Primary hospital & 52.52 & Primary hospital visit & 18.58 \\
\hline Secondary hospital & 54.76 & $\begin{array}{l}\text { Secondary hospital } \\
\text { visit }\end{array}$ & 21.17 \\
\hline Tertiary hospital & 70.81 & Tertiary hospital visit & 22.06 \\
\hline \multicolumn{2}{|c|}{$\begin{array}{l}\text { Percutaneous coronary interven- } \\
\text { tion }^{\mathrm{a}} 63,000\end{array}$} & Health center visit & 23.00 \\
\hline \multicolumn{4}{|c|}{ Source:WHO_CHOICE [69] } \\
\hline \multicolumn{4}{|c|}{ Laboratory and imaging } \\
\hline $\begin{array}{l}\text { Complete blood } \\
\text { count }\end{array}$ & 20 & Blood glucose & 10 \\
\hline $\begin{array}{l}\text { Prothrombin time } \\
\text { (INR) }\end{array}$ & 15 & Urinalysis & 5 \\
\hline aPTT & 15 & Liver function test & 30 \\
\hline Serum electrolytes & 45 & Total cholesterol & 7 \\
\hline Renal function test & 20 & Serum lipids & 42 \\
\hline Blood glucose & 10 & CTscan & 600 \\
\hline Echocardiography & 150 & Endoscopy & 400 \\
\hline \multicolumn{4}{|c|}{ Source: Tikur Anbesa teaching hospital and Zewditu memorial hospital } \\
\hline \multicolumn{4}{|l|}{ Drugs } \\
\hline ASA $100 \mathrm{mg}$ & 0.08 & Simvastatin $20 \mathrm{mg}$ & 0.25 \\
\hline Enalapril $10 \mathrm{mg}$ & 0.05 & Streptokinase $1.5 \mathrm{iu}$ & 601.8 \\
\hline \multirow[t]{2}{*}{ Atenolol $50 \mathrm{mg}$} & 0.06 & Clopidogrel $75 \mathrm{mg}$ & 0.55 \\
\hline & & $\begin{array}{l}\text { Hydrochlorothiazide } \\
25 \mathrm{mg}\end{array}$ & 0.08 \\
\hline
\end{tabular}

Source: International drug price indicator [57]

a Unit price per procedure. The program cost was assumed to be double the program cost required for other acute myocardial infarction interventions

\section{Uncertainty analysis}

A probabilistic sensitivity analysis was conducted using Monte Carlo League (MCLeague) software to assess the effect of uncertainty surrounding the costs and effectiveness estimates [58]. A truncated normal distribution was used to execute 1000 simulation runs with 15 and $25 \%$ coefficient of variation for costs and effectiveness estimates, respectively. We assessed interventions that were not dominated by respective comparators in each intervention category. In addition, one-way sensitivity analysis was undertaken, applying the lower boundary of the effectiveness range; doubling the price of drugs, procedures and laboratory tests; a zero discounting rate to health benefits; and applying $50 \%$ of the effectiveness point estimates (Tables 1, 2).

\section{Results}

Treatment of acute myocardial infarction with ACEinhibitor costs the least at US\$2.4 million annually. Combination drug treatment to individuals having $>5 \%$ absolute risk of developing a CVD event incurs the highest annual cost US\$26.9 million- and generates the highest annual health benefit of 190,000 DALYs averted. Treatment of acute stroke with aspirin generates the smallest annual health benefit. The estimated annual costs, health benefits, ACER and ICERs for all interventions are presented in Table 4 below.

The absolute risk-based approach turns out to be the most cost-effective strategy of all the interventions. Combination drug treatment to individuals having an absolute risk $>35 \%$ yields the most value for money with an ICER of US $\$ 67$ per DALY averted, with ICER reaching US\$340 per DALY averted when the risk threshold is lowered to $>5 \%$. When compared with the single riskfactor based approach, the absolute risk-based approach is the most cost-effective option. Notably, initiating treatment at higher CVD risk threshold generates better efficiency gain compared to lower risk thresholds regardless of the approach chosen. This means, for example, that initiating anti-hypertensive drug treatment at SBP of $>160 \mathrm{mmHg}$ is more efficient than treatment at $>140 \mathrm{mmHg}$. Of all the interventions for AMI, an integrated package of aspirin, ACE-inhibitors, betablockers and streptokinase has the lowest ICER (i.e., US\$999 per DALY averted). Provision of interventions in an integrated package generates better efficiency gain and dominates all the single interventions, as shown in Table 4. Moving from the most cost-effective pharmaceutical package to an integrated package that includes the highly skilled intervention PCI, aspirin and clopidogrel raised the ICER substantially-to US $\$ 5087$ per one additional DALY averted.

Treatment of acute ischemic stroke with aspirin costs US $\$ 40,000$ per DALY averted. Single drug interventions for secondary prevention of IHD and stroke cost between US $\$ 2400$ and US\$10,300 per DALY averted respectively. Interventions become more efficient when delivered in an integrated package. A package consisting of aspirin, beta-blocker ACE-inhibitor and statin for secondary prevention of IHD costs US\$1850 per DALY averted, while a package consisting of aspirin, ACE-inhibitor and statins for secondary prevention of stroke costs US\$1060 per DALY averted. 
Table 4 Annual cost, annual health benefits and cost-effectiveness ratio of selected CVD interventions in Ethiopia

\begin{tabular}{|c|c|c|c|c|c|}
\hline Intervention description & $\begin{array}{l}\text { Annual cost in } \\
\text { million US\$ }\end{array}$ & $\begin{array}{l}\text { Annual DALYs averted } \\
\text { (discounted) }\end{array}$ & $\begin{array}{l}\text { Annual DALYs averted } \\
\text { (undiscounted) }\end{array}$ & ACER & ICER \\
\hline \multicolumn{6}{|l|}{ Acute myocardial infarction } \\
\hline ACE-inhibitor & 2.37 & 316 & 422 & 7531 & Dominated \\
\hline Beta-blocker & 2.38 & 586 & 784 & 4057 & Dominated \\
\hline ASA & 2.38 & 990 & 1325 & 2200 & Dominated \\
\hline Streptokinase & 2.82 & 1170 & 1566 & 2408 & Dominated \\
\hline ASA + clopidogrel & 2.38 & 1441 & 1927 & 1556 & Dominated \\
\hline ASA + streptokinase & 2.84 & 2110 & 2822 & 1295 & Dominated \\
\hline $\begin{array}{l}\text { ASA + streptokinase + ACE- } \\
\text { inhibitor }\end{array}$ & 2.85 & 2396 & 3205 & 1149 & Dominated \\
\hline Primary $\mathrm{PCl}$ & 8.29 & 2747 & 3675 & 3013 & Dominated \\
\hline $\begin{array}{l}\text { ASA + streptokinase + ACE- } \\
\text { inhibitor + beta-blocker }\end{array}$ & 2.92 & 2919 & 3905 & 999 & 999 \\
\hline $\mathrm{ASA}+$ clopidogrel $+\mathrm{PCl}$ & 8.5 & 4015 & 5370 & 2115 & 5087 \\
\hline \multicolumn{6}{|l|}{ Acute stroke } \\
\hline ASA & 2.53 & 63 & 80 & 39,892 & 39,892 \\
\hline \multicolumn{6}{|l|}{ Post-acute IHD } \\
\hline ASA & 2.54 & 245 & 330 & 10,345 & Dominated \\
\hline Statin & 2.74 & 310 & 417 & 8822 & Dominated \\
\hline Beta-blocker & 2.53 & 488 & 657 & 5177 & Dominated \\
\hline ACE-inhibitor & 2.55 & 524 & 705 & 4857 & Dominated \\
\hline ASA + beta-blocker & 2.57 & 732 & 985 & 3511 & Dominated \\
\hline ASA + beta-blocker + statin & 2.82 & 1038 & 1397 & 2717 & Dominated \\
\hline $\begin{array}{l}\text { ASA + beta-blocker + sta- } \\
\text { tin + ACE-inhibitor }\end{array}$ & 2.88 & 1557 & 2096 & 1849 & 1849 \\
\hline \multicolumn{6}{|l|}{ Post-acute stroke } \\
\hline ACE-inhibitor & 2.87 & 912 & 1200 & 3153 & Dominated \\
\hline ASA & 2.86 & 1013 & 1348 & 2821 & Dominated \\
\hline Statin & 3.30 & 1375 & 1813 & 2396 & Dominated \\
\hline$A S A+$ statin & 3.40 & 2382 & 3150 & 1428 & Dominated \\
\hline ASA + statin + ACE-inhibitor & 3.48 & 3284 & 4337 & 1061 & 1061 \\
\hline \multicolumn{6}{|c|}{ Primary prevention of $\mathrm{IHD}$ and stroke } \\
\hline $\begin{array}{c}\text { Cholesterol lowering } \\
\text { treatment for total } \\
\text { chol. }>6.2 \mathrm{mmol} / \mathrm{l}\end{array}$ & 4.67 & 8768 & 15,913 & 532 & Dominated \\
\hline $\begin{array}{l}\text { Cholesterol lowering } \\
\text { treatment for total } \\
\text { chol. }>5.7 \mathrm{mmol} / \mathrm{l}\end{array}$ & 10.62 & 19,073 & 34,143 & 557 & Dominated \\
\hline $\begin{array}{l}\text { Anti-hypertension treatment } \\
\text { for SBP }>160 \mathrm{mmHg}\end{array}$ & 7.33 & 98,880 & 172,868 & 74 & Dominated \\
\hline $\begin{array}{l}\text { Combination drug treat- } \\
\text { ment for absolute risk of } \\
\text { CVD }>35 \%\end{array}$ & 7.18 & 107,687 & 185,249 & 67 & 67 \\
\hline $\begin{array}{l}\text { Anti-hypertension treatment } \\
\text { for SBP }>140 \mathrm{mmHg}\end{array}$ & 19.42 & 125,712 & 220,992 & 154 & Dominated \\
\hline $\begin{array}{l}\text { Combination drug treat- } \\
\text { ment for absolute risk of } \\
\text { CVD }>25 \%\end{array}$ & 9.83 & 127,957 & 219,230 & 77 & 131 \\
\hline $\begin{array}{l}\text { Combination drug treat- } \\
\text { ment for absolute risk of } \\
\text { CVD }>15 \%\end{array}$ & 14.41 & 153,877 & 263,747 & 94 & 177 \\
\hline $\begin{array}{l}\text { Combination drug treat- } \\
\text { ment for absolute risk of } \\
\text { CVD }>5 \%\end{array}$ & 26.85 & 190,391 & 329,117 & 141 & 341 \\
\hline
\end{tabular}


In order to facilitate step-wise selection of the most cost-effective interventions, interventions that dominate their comparators in each category were ranked according to their category-specific ICER. Accordingly, combination drug treatment to individuals having $>35 \%$ absolute risk of developing a CVD event is the first intervention to be selected, followed by the same intervention at lower risk thresholds ( $>25,>15$ and $>5 \%$, respectively). A basic integrated package of aspirin, ACE-inhibitor, beta-blocker and streptokinase for AMI and a package of aspirin, statin and ACE-inhibitor for secondary prevention of stroke are the next two interventions that could be selected when more resources become available. Scale-up of combination drug treatment at an absolute risk $>35 \%$ to a coverage level of $20 \%$ costs about US\$7 million per year and averts 107,000 DALYs annually.

Table 5 presents the results from the one-way sensitivity analysis. At the lower boundary of the effectiveness range, all interventions become less cost-effective. The ACERs increased by a factor of 1.5-to sixfold for AMI and secondary prevention interventions. Primary prevention interventions were less sensitive. Halving the point estimates for effectiveness has a relatively larger impact on the primary prevention interventions, with respective ACERs increasing by a factor of 1.4-1.8. However, even at half point estimate of effectiveness, combination drug treatment to individuals having $>35 \%$ CVD risk costs US\$94 per DALY averted. Doubling the price of drugs and laboratory tests increases ACERs minimally compared with halving or applying lower limit of effectiveness estimates. All the interventions become more cost-effective at a zero discounting rate for the health benefits (Table 5).

The probabilistic sensitivity analysis illustrates the serious uncertainty surrounding our results, with wide and overlapping uncertainty ranges for cost and effectiveness estimates (Fig. 1). Budget size has considerable impact on the probability of interventions being cost-effective. At an annual budget of US\$3-US\$4 million, an integrated package consisting of ASA, streptokinase, ACE-inhibitor and beta-blocker for AMI has the highest probability (0.50) of being the most cost-effective approach. Between US\$4 and US\$7 million, the probability curve for a secondary prevention package for stroke consisting of aspirin, ACE-inhibitor and statin overlaps on the basic AMI package, making the choice less straight forward. As the budget increases to more than US $\$ 7$ million per year, combination drug treatment to individuals having more than $35 \%$ absolute risk of CVD stands out as the most cost-effective intervention. However, even at this budget level, the other interventions have less but meaningful probability of being cost-effective (Fig. 2).

\section{Discussion}

Our analysis illustrates that primary prevention of ischemic heart disease and stroke is a more efficient strategy for maximizing population-level health benefits compared with acute treatment and secondary prevention. All primary prevention interventions cost less than US\$ 560 per DALY averted. The absolute risk-based approach is more cost-effective than the single risk-factor approaches for primary prevention of CVD. This corresponds with the findings of similar studies for the subSaharan Africa region and other regions [23, 24]. The superiority of the absolute risk-based approach is primarily explained by: (a) the linear nature of the correlation between blood pressure and cholesterol level with the risk of CVD event and (b) the tendency for co-existence and interaction between CVD risk factors [19, 59, 60]. The modest 'efficiency loss' related to lowering the risk thresholds is due to the larger number of eligible individuals significantly increasing the cost for a relatively modest additional health benefits. It is therefore worthwhile to set the CVD risk threshold at $>35 \%$ initially; this can be lowered when more resources become available. The proposed risk threshold of $>35 \%$ accords with WHO's recommendation for resource-limited settings like Ethiopia [18].

All the single pharmacologic interventions for treatment of AMI were dominated by the integrated package consisting of aspirin, ACE-inhibitor, beta-blocker and streptokinase. Delivering interventions in integrated packages yields significant efficiency gain due to savings from program costs and patient costs [23]. This is comparable with the results from the Disease Control Priorities project 2nd edition [61]. Interestingly, the ICER escalates by about six fold if one moves from this basic pharmaceutical package to a highly skilled intervention consisting of PCI, aspirin, and clopidogrel. Although PCI is the treatment of choice for AMI in ideal settings [41, 62], our results indicate the need to prioritize the scale-up of basic pharmacologic regimens for AMI treatment in resourceconstrained settings like Ethiopia rather than investing the limited resources on high-standard interventions.

An integrated package of aspirin, beta-blocker, ACEinhibitor and statin for secondary prevention of IHD and a package of aspirin, ACE-inhibitor and statin for secondary prevention of stroke appears to be the preferred options within their categories. This is in line with the findings of Ortegon et al. for the sub-Saharan Africa region [23]. On the grounds of cost-effectiveness, secondary prevention interventions are ranked lower than primary prevention interventions. This is partly because primary prevention interventions generate a larger population-level aggregate health benefit with relatively lower unit delivery costs [23]. In addition, the need for 
Table 5 Average cost-effectiveness ratios for cardiovascular disease interventions under multiple scenarios

\begin{tabular}{|c|c|c|c|c|c|c|}
\hline Intervention description & Base-case & $\begin{array}{l}\text { Undiscounted } \\
\text { health benefits }^{\mathrm{a}}\end{array}$ & $10 \%$ coverage $^{\mathbf{b}}$ & Double cost ${ }^{c}$ & Lower effect $^{d}$ & $50 \%$ effect $^{\mathrm{e}}$ \\
\hline \multicolumn{7}{|l|}{ Acute myocardial infarction } \\
\hline ACE-inhibitor & 7526 & 5626 & 14,718 & 7777 & 26,556 & 15,172 \\
\hline Beta-blocker & 4054 & 3031 & 7926 & 4191 & 26,556 & 8171 \\
\hline ASA & 2398 & 1792 & 4685 & 2480 & 3545 & 4831 \\
\hline Streptokinase & 2407 & 1799 & 4343 & 2855 & 3714 & 4850 \\
\hline ASA + clopidogrel & 1652 & 1235 & 3225 & 1712 & 2958 & 3327 \\
\hline ASA + streptokinase & 1345 & 1006 & 2419 & 1603 & 2015 & 2669 \\
\hline ASA + streptokinase + ACE-inhibitor & 1188 & 888 & 2133 & 1411 & 1903 & 2342 \\
\hline Primary $\mathrm{PCl}$ & 3013 & 2252 & 4560 & 4460 & 4833 & 5983 \\
\hline $\begin{array}{l}\text { ASA + streptokinase + ACE-inhibi- } \\
\text { tor + beta-blocker }\end{array}$ & 998 & 746 & 1774 & 1210 & 1839 & 1950 \\
\hline $\mathrm{ASA}+$ clopidogrel $+\mathrm{PCl}$ & 2112 & 1579 & 3171 & 2240 & 3410 & 4062 \\
\hline \multicolumn{7}{|l|}{ Acute stroke } \\
\hline ASA & 39,896 & 31,586 & 75,658 & 42,135 & 99,269 & 79,449 \\
\hline \multicolumn{7}{|l|}{ Post-acute myocardial infarction } \\
\hline ASA & 10,345 & 7701 & 19,853 & 11,173 & 50,593 & 19,029 \\
\hline Statin & 8822 & 6552 & 16,139 & 10,119 & 10,659 & 11,594 \\
\hline Beta-blocker & 5177 & 3844 & 9823 & 5575 & 7386 & 10,296 \\
\hline ACE-inhibitor & 4856 & 3612 & 9182 & 5264 & 6092 & 6771 \\
\hline ASA + beta-blocker & 3512 & 2610 & 6612 & 3835 & 6556 & 6793 \\
\hline ASA + beta-blocker + statin & 2717 & 2018 & 4904 & 3182 & 4351 & 4597 \\
\hline $\begin{array}{l}\text { ASA + beta-blocker + statin + ACE- } \\
\text { inhibitor }\end{array}$ & 1849 & 1373 & 3349 & 2197 & 2704 & 2908 \\
\hline \multicolumn{7}{|l|}{ Post-acute stroke } \\
\hline ACE-inhibitor & 3152 & 2394 & 5642 & 3663 & 3153 & 3153 \\
\hline ASA & 2822 & 2121 & 5065 & 3264 & 9996 & 4833 \\
\hline Statin & 2397 & 1820 & 4046 & 3042 & 3427 & 4355 \\
\hline ASA + statin & 1429 & 1080 & 2382 & 1844 & 2730 & 2528 \\
\hline ASA + statin + ACE-inhibitor & 1061 & 803 & 1751 & 1386 & 1616 & 1545 \\
\hline \multicolumn{7}{|l|}{ Primary prevention of IHD and stroke } \\
\hline $\begin{array}{l}\text { Cholesterol lowering treatment for } \\
\text { total chol. }>6.2 \mathrm{mmol} / \mathrm{l}\end{array}$ & 532 & 293 & 791 & 738 & 605 & 941 \\
\hline $\begin{array}{l}\text { Cholesterol lowering treatment for } \\
\text { total chol. }>5.7 \mathrm{mmol} / \mathrm{l}\end{array}$ & 557 & 311 & 676 & 888 & 636 & 1002 \\
\hline $\begin{array}{l}\text { Anti-hypertension treatment for } \\
\quad \mathrm{SBP}>160 \mathrm{mmHg}\end{array}$ & 74 & 42 & 97 & 102 & 77 & 124 \\
\hline $\begin{array}{l}\text { Combination drug treatment for } \\
\text { absolute risk of CVD }>35 \%\end{array}$ & 67 & 39 & 88 & 103 & 69 & 94 \\
\hline $\begin{array}{l}\text { Anti-hypertension treatment for } \\
\quad \mathrm{SBP}>140 \mathrm{mmHg}\end{array}$ & 154 & 88 & 172 & 234 & 161 & 263 \\
\hline $\begin{array}{l}\text { Combination drug treatment for } \\
\text { absolute risk of CVD }>25 \%\end{array}$ & 77 & 45 & 95 & 124 & 80 & 108 \\
\hline $\begin{array}{l}\text { Combination drug treatment for } \\
\text { absolute risk of CVD }>15 \%\end{array}$ & 94 & 55 & 108 & 157 & 98 & 132 \\
\hline $\begin{array}{l}\text { Combination drug treatment for } \\
\text { absolute risk of CVD }>5 \%\end{array}$ & 141 & 82 & 153 & 245 & 148 & 199 \\
\hline
\end{tabular}

a Undiscounted health benefits

b $10 \%$ target coverage

c Double price for drugs, procedures and laboratory test

d Lower boundary of effectiveness estimate

e $50 \%$ of point estimate of effectiveness 


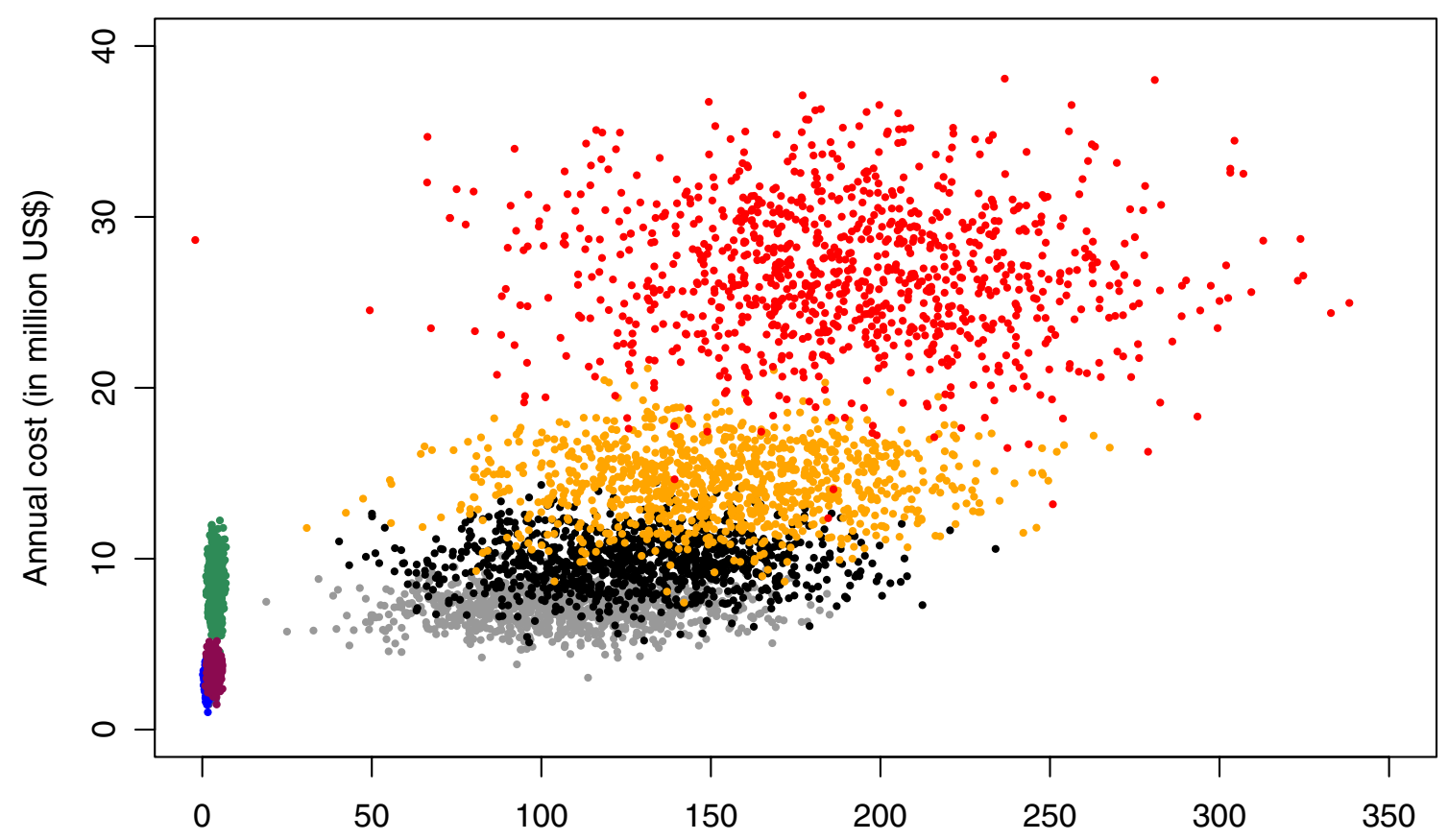

Annual health benefits (in 1,000 DALYs averted)

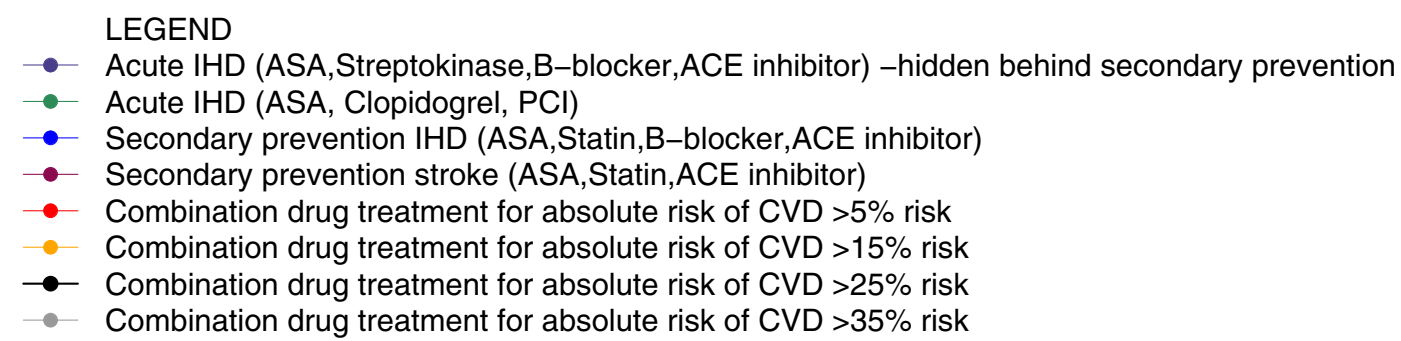

Fig. 1 Probabilistic sensitivity analysis of non-dominated CVD interventions in Ethiopia

relatively more frequent follow-up visits at primary hospital level for secondary prevention interventions partly explains higher cost-effectiveness ratios as compared with primary prevention interventions.

Continuing controversy about appropriate thresholds for cost-effectiveness ratios highlights the need for more empirical work in that area [50,63, 64]. Woods et al. suggested a very low CER threshold of about $50 \%$ of GDP per capita compared with WHO's recommendation of 1-3 times GDP per capita, which translates to US\$505US $\$ 1515$ for the year 2013 [50, 63, 64]. Determining the appropriate cost-effectiveness ratio threshold level is beyond the scope of this paper, we therefore discuss the implications of scaling-up the intervention with the lowest ICER and leave the decision to policymakers to further select interventions that best fit the local budget constraint. Accordingly, combination drug treatment to individuals having more than $35 \%$ absolute risk of CVD event is a reasonable starting point. Scale-up of this intervention to a coverage level of $20 \%$ averts 107,000 DALYs annually at a cost of about US\$ 7 million per year. This is equivalent to $0.4 \%$ of the $2010 / 11$ annual total health expenditure for Ethiopia [21]. In terms of GDP per capita, the ICER is about $13 \%$ of GDP per capita for 2013.

With the evident escalating burden from CVD and its risk factors $[5,7,11,12]$, investing in primary prevention early on could help Ethiopia partially reduce the need to invest in more costly acute care and secondary prevention measures in the long term. Notably, the most cost-effective combination drug treatment based on an absolute risk approach could be scaled up at the primary health care level, for which Ethiopia has already 


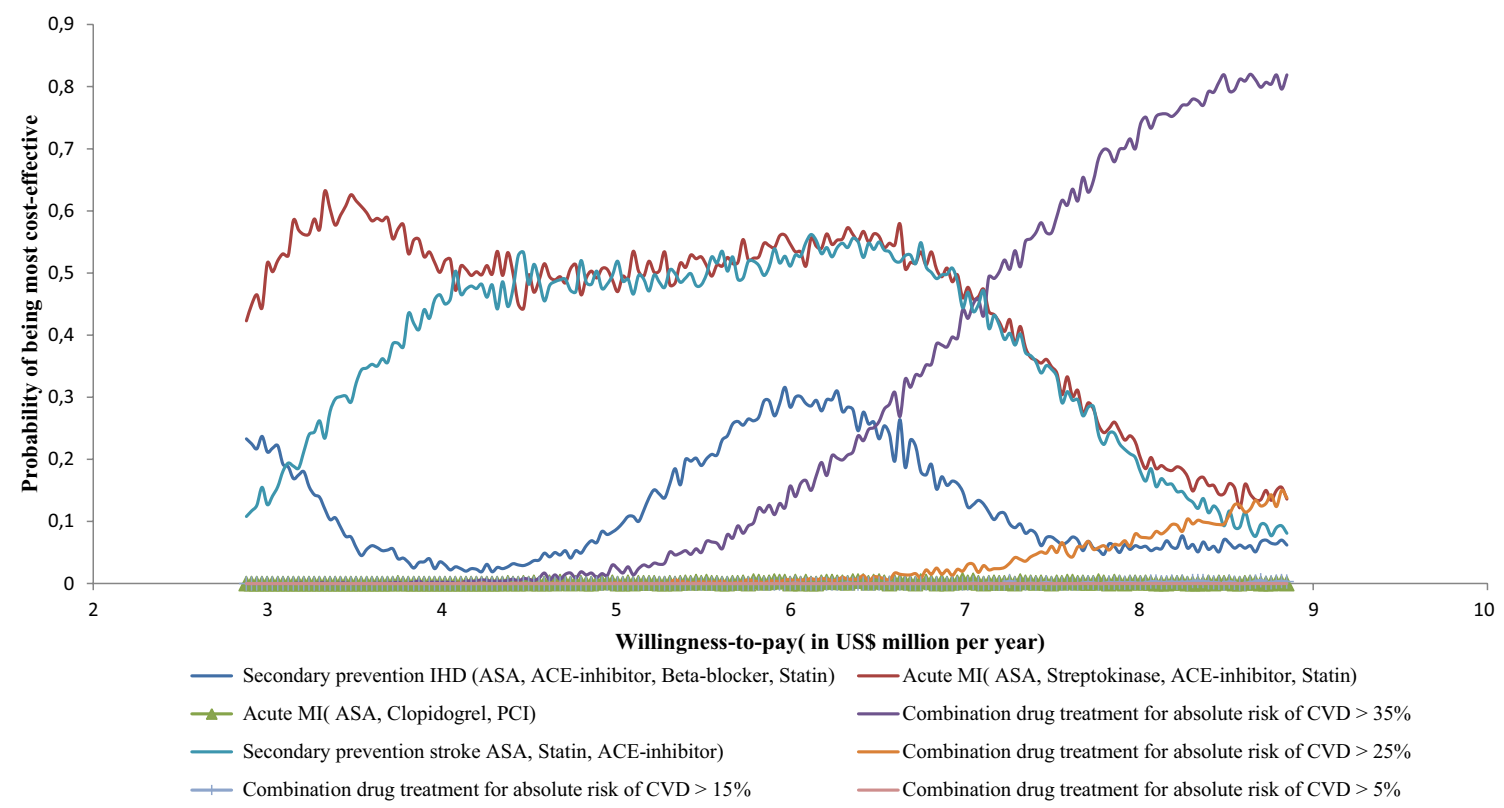

Fig. 2 Probabilistic sensitivity analysis of non-dominated CVD interventions in Ethiopia

established a solid foundation [30]. This could facilitate scaling up of the proposed primary prevention interventions at a more modest additional resource requirement than originally estimated. The actual budget implication, however, needs to be assessed separately using appropriate tools.

However, based on the probabilistic sensitivity analysis, the choice of intervention depends on the level of willingness-to-pay. When resources are scarce $(<$ US $\$ 7$ million annually), a package consisting of aspirin, streptokinase, ACE-inhibitor and beta-blocker for AMI is a preferred option over combination drug treatment for an absolute risk of CVD $>35 \%$, although it ranked lower based on the ICER. It is also worth noting that CEA results are only one of the key parameters to be considered in priority setting. Policy makers need to take into account other important parameters for fair resource allocation, such as severity of disease, equity and financial risk protection [65].

Our study has a number of limitations. We have not included all possible sets of CVD interventions in our analysis. In the absence of country-level data on epidemiology of ischemic heart disease, stroke and the risk factors (incidence, prevalence, and case fatality rate), such estimates were drawn from estimates for the East Africa region. For the same reason, the effectiveness estimates for interventions were drawn from studies in developed settings. This may introduce bias into our cost-effectiveness ratio estimates, as it may be unrealistic to attain the same health benefit level from interventions in an
Ethiopian setting; reasons for this may include differences in quality of health services, availability of resources and skilled human resources.

Interventions' effect is assumed to be uniform across sub-groups with varying risk level. This may have resulted in an overestimation of the potential impact of interventions in individuals with relatively lower risk and underestimation of the potential impact in high risk group. Therefore, detection of the direction of the bias on the final results is not straight forward; our intuition is that the net effect on the final results is very minimal.

PopMod estimates interventions' health benefits by tracing what would happen to the population with and without the interventions over a lifetime of 100 years. The interventions are assumed to be implemented only for the first 10-year period; the epidemiologic rates are subsequently returned to the 'no intervention' level. This only partially captures intervention health benefits; possible extended benefits from interventions on the outcome of interest are missed, resulting in possible underestimation of interventions' relative cost-effectiveness. Intervention period of more than 10 years involves a high degree of uncertainty and it is difficult to predict how CVD interventions may look like after 10 years from now.

Given the healthcare provider perspective we adopted for the analyses, we have not considered patient and caregiver costs such as transportation and cost of time lost while seeking healthcare. In addition, out-of-pocket expenditure by households constitutes one-third of total 
health spending in Ethiopia [21]. Such factors might influence households' decision to access especially prevention strategies that entail repeated visits to health facilities and this aspect requires further exploration.

For primary prevention interventions, we did not consider the cost of screening all eligible individuals to identify 'at risk' sub-population groups. Scaling up screening programs could be very costly in low-income settings like Ethiopia [19]; therefore we included the cost of a health center visit and laboratory test only for those identified as 'at risk' through opportunistic screening. This would underestimate the potentially huge cost screening could entail at population level.

In addition to the proposed interventions, the potential benefit from sustained life style modification among the public cannot be over-stated for successful prevention and control of CVD in Ethiopia [19].

\section{Conclusions}

In Ethiopia, the escalating burden from CVD and its risk factors warrants timely action. We have demonstrated that selected packages CVD interventions could be scaled up in Ethiopia at a modest budget increase and that combination drug treatment to individuals having more than $35 \%$ absolute risk of CVD event is the most cost-effective intervention. However, the level of willingness-to-pay has important implications for interventions' probability of being most cost-effective. The study provides valuable evidence for setting priorities in an essential health care package for cardiovascular diseases in Ethiopia.
Addis Ababa, Ethiopia. ${ }^{5}$ World Health Organization, Geneva, Switzerland. ${ }^{6}$ Department of Global Health and Population, Harvard T.H. Chan School of Public Health, Boston, MA, USA.

\section{Acknowledgements}

Our appreciation goes to the Norwegian Research Council and the Bill and Melinda Gates Foundation for their generous funding to undertake this research. We would also like to thank the research group at the Department of Global Public Health and Primary Care for their constructive feedback in the development of the manuscript.

\section{Competing interests}

The funding agents had no role in the design, analysis and write-up of the manuscript, and the views expressed in the manuscript reflect only the authors' view and not that of any organization. The authors declare that they have no competing interests.

\section{Availability of data and materials}

The dataset supporting the conclusions in this article could be made available up on request. However, it is worth noting that the analysis is done based on a publicly available cardiovascular disease model for Africa region East (AfrE) developed by WHO-CHOICE. All updates made as part of the contextualization have been described in the text, and the assumptions that went into the model have been provided in Tables 1, 2 and 3.

\section{Ethics approval and consent to participate}

Ethical approval was not required for this study as it is entirely based on publicly available data. The study didn't involve individual-persons' level data.

\section{Funding}

This work was mainly supported by the Norwegian Research Council through the Global Health Priorities 2020 project (Project Number: 218694/H10) and partially funded by the Bill and Melinda Gates Foundation through the Disease Control Priorities Network grant and the Disease Control Priorities-Ethiopia effort.

Received: 16 December 2015 Accepted: 3 August 2016

Published online: 12 August 2016

\begin{abstract}
Abbrevations
ACE-inhibitor: angiotensin converting enzyme inhibitors; ACER: average costeffectiveness ratio; AMI: acute myocardial infarction; $C B C$ : complete blood count; CEA: cost-effectiveness analysis; CHOICE: choosing inteventions that are cost-effective; CVD: cardiovascular disease; DALYs: disability-adjusted life years; ECG: electrocardiogram; FMOH: Federal Ministry of Health; GDP: gross domestic product; ICER: incremental cost-effectiveness ratio; IHD: ischemic heart disease; INR: international normalized ratio; LFT: liver function test; LMIC: low- and middle-income countries; NCD: non-communicable disease; NSAP: national strategic action plan; $\mathrm{PCl}$ : percutaneous coronary intervention; PT: prothrombin time; RFT: renal function test; SBP: systolic blood pressure; SSA: sub-Saharan Africa; US: United States; WHO: World Health Organization.
\end{abstract}

\section{Authors' contributions}

MT, KAJ and KPS led the design of the study. MT and KAJ performed the analysis. KPS, STM and MB helped in the analysis. MT coordinated the overall research and was responsible for writing of the manuscript and incorporating feedbacks. AA and DJ contributed in collecting local data on the price of nontraded goods. DJ, SGA, AA, STM, KPS, OLF, SV and KAJ reviewed the manuscript and provided feedback. MT is responsible for finalization and submission of the final manuscript for publication. All authors read and approved the final manuscript.

\section{Author details}

${ }^{1}$ Department of Global Public Health and Primary Health Care, University of Bergen, Bergen, Norway. ${ }^{2}$ Department of Internal Medicine, School of Medicine, Addis Ababa University, Addis Ababa, Ethiopia. ${ }^{3}$ Federal Ministry of Health (FMOH), Addis Ababa, Ethiopia. ${ }^{4}$ Management Science for Health,

\section{References}

1. Naghavi M, et al. Global, regional, and national age-sex specific all-cause and cause-specific mortality for 240 causes of death, 1990-2013: a systematic analysis for the Global Burden of Disease Study 2013. Lancet. 2015:385(9963):117-71.

2. Abegunde DO, et al. The burden and costs of chronic diseases in lowincome and middle-income countries. Lancet. 2007:370(9603):1929-38.

3. WHO. WHO Africa Region: Ethiopia, Noncommunicable disease. 2014. http://www.who.int/countries/eth/en/. Accessed 20 Jan 2015.

4. Zenebe $\mathrm{G}$, Alemayehu M, Asmera J. Characteristics and outcomes of stroke at Tikur Anbessa Teaching Hospital, Ethiopia. Ethiop Med J. 2005:43(4):251-9.

5. Tesfaye F, Byass P, Wall S. Population based prevalence of high blood pressure among adults in Addis Ababa: uncovering a silent epidemic. BMC Cardiovasc Disord. 2009;9(1):39.

6. Gudina EK, Michael Y, Assegid S. Prevalence of hypertension and its risk factors in southwest Ethiopia: a hospital-based cross-sectional survey. Integr Blood Press Control. 2013:6:111.

7. Misganaw A, et al. Patterns of mortality in public and private hospitals of Addis Ababa, Ethiopia. BMC Public Health. 2012;12(1):1007.

8. Misganaw A, Mariam DH, Araya T. The double mortality burden among adults in Addis Ababa, Ethiopia, 2006-2009. Prev Chronic Dis. 2012;9:E84.

9. Alemayehu CM, Birhanesilasie SK. Assessment of stoke patients: occurrence of unusually high number of haemorrhagic stroke cases in Tikur Anbessa Specialized Hospital, Addis Ababa, Ethiopia. Clin Med Res. 2013;2(5):94-100

10. Alemayehu B, Oli K. Stroke admission to Tikur Anbassa Teaching Hospital: with emphasis on stroke in the young. Ethiop J Health Dev. 2002:16(3):309-15. 
11. Habte B, Alemseged F, Tesfaye D. The pattern of cardiac diseases at the cardiac clinic of Jimma University specialised hospital, south West Ethiopia. Ethiop J Health Sci. 2010;20(2):99-105.

12. Abdisa SG, Oli K, Feleke Y, Goshu DY, Begna DM, Tafese A. Spectrum of cardiovascular diseases among Ethiopian patients at Tikur Anbessa Specialized University Teaching Hospital, Addis Ababa. Ethiop Medl J. 2014;52(1):9-17.

13. Bonsa F, Gudina EK, Hajito KW. Prevalence of hypertension and associated factors in Bedele Town, Southwest Ethiopia. Ethiop J Health Sci. 2014;24(1):21-6.

14. Awoke $\mathrm{A}$, et al. Prevalence and associated factors of hypertension among adults in Gondar, Northwest Ethiopia: a community based cross-sectional study. BMC Cardiovasc Disord. 2012;12(1):113.

15. Misganaw A, et al. Epidemiology of major non-communicable diseases in Ethiopia: a systematic review. J Health Popul Nutr. 2014;32(1):1.

16. Mendis S, Puska P, Norrving B. Global atlas on cardiovascular disease prevention and control. Geneva: World Health Organization; 2011.

17. Steyn $\mathrm{K}$, et al. Risk factors associated with myocardial infarction in Africa the INTERHEART Africa Study. Circulation. 2005;112(23):3554-61.

18. WHO. Package of essential noncommunicable (PEN) disease interventions for primary health care in low-resource settings. Cardiovascular diseases 2010. http://www.who.int/cardiovascular_diseases/publications/pen2010/en/. Accessed 09 Dec 2015.

19. WHO. Guidelines for assessment and managment of cardiovascular risk 2007. http://www.who.int/cardiovascular_diseases/publications/Prevention_of_Cardiovascular_Disease/en/. Accessed 09 Dec 2015.

20. Federal Ministry of Health, E. Prevention and control of non-communicable diseases and their risk factors in Ethiopia: National Strategic Action Plan. 2014-2016. Accessed 20 Mar 2015.

21. FMOH-USAID. National Health Accounts-V. 2010/11. http://www.hfgproject.org/.../Ethiopia-NHA-Household-Survey..../. Accessed 03 Sept 2015.

22. WHO. Cost effectiveness and strategic planning (WHO-CHOICE). http:// www.who.int/choice/interventions/en/. Accessed 28 Mar 2015.

23. Ortegón $M$, et al. Cost effectiveness of strategies to combat cardiovascular disease, diabetes, and tobacco use in sub-Saharan Africa and South East Asia: mathematical modelling study. BMJ. 2012;344:e607.

24. Murray CJ, et al. Effectiveness and costs of interventions to lower systolic blood pressure and cholesterol: a global and regional analysis on reduction of cardiovascular-disease risk. Lancet. 2003;361(9359):717-25.

25. Hutubessy R, Chisholm D, Edejer TT. Generalized cost-effectiveness analysis for national-level priority-setting in the health sector. Cost Eff Resour Alloc. 2003;1(1):8

26. Strand $K B$, et al. Scaling-up essential neuropsychiatric services in Ethiopia: a cost-effectiveness analysis. Health Policy Plan. 2016;31(4):504-13. doi:10.1093/heapol/czv093.

27. Ha DA, Chisholm D. Cost-effectiveness analysis of interventions to prevent cardiovascular disease in Vietnam. Health Policy Plan. 2011;26(3):210-22.

28. WHO. WHO guide to cost-effectiveness analysis. 2003. http://www.who. int/choice/publications/p_2003_generalised_cea.pdf. Accessed 28 Mar 2015.

29. WorldBank. Ehiopia: World development indicators. 2012/13. http://www. data.worldbank.org/country/ethiopia. Accessed 03 Sept 2015.

30. Federal Ministry of Health, E. Annual performance report 2006EFY. http:// www.moh.gov.et/resources. Accessed 20 Feb 2015.

31. Ezzati M, Lopez AD. Smoking and oral tobacco use. Comparative quantification of health risks. Geneva: WHO Publications; 2004.

32. Trialists'Collaboration, A. Collaborative meta-analysis of randomised trials of antiplatelet therapy for prevention of death, myocardial infarction, and stroke in high risk patients. BMJ. 2002;324(7329):71-86.

33. Keeley EC, Boura JA, Grines CL. Comparison of primary and facilitated percutaneous coronary interventions for ST-elevation myocardial infarction: quantitative review of randomised trials. Lancet. 2006;367(9510):579-88.

34. Doll R. Addition of clopidogrel to aspirin in 45,852 patients with acute myocardial infarction: randomised placebo-controlled trial. Lancet. 2005:366:1607-21.

35. Hebert PR, et al. Cholesterol lowering with statin drugs, risk of stroke, and total mortality: an overview of randomized trials. JAMA. 1997;278(4):313-21.
36. Baigent $C$, et al. ISIS-2: 10 year survival among patients with suspected acute myocardial infarction in randomised comparison of intravenous streptokinase, oral aspirin, both, or neither. BMJ. 1998;316(7141):1337.

37. Wood AJ, et al. Adjunctive drug therapy of acute myocardial infarctionevidence from clinical trials. N Engl J Med. 1996;335(22):1660-8.

38. LaRosa JC, He J, Vupputuri S. Effect of statins on risk of coronary disease: a meta-analysis of randomized controlled trials. JAMA. 1999;282(24):2340-6.

39. Gutierrez J, et al. Statin therapy in the prevention of recurrent cardiovascular events: a sex-based meta-analysis. Arch Intern Med. 2012;172(12):909-19.

40. Collaboration, B.P.L.T.T. Effects of ACE inhibitors, calcium antagonists, and other blood-pressure-lowering drugs: results of prospectively designed overviews of randomised trials. Lancet. 2000;356(9246):1955-64.

41. Keeley EC, Boura JA, Grines CL. Primary angioplasty versus intravenous thrombolytic therapy for acute myocardial infarction: a quantitative review of 23 randomised trials. Lancet. 2003;361(9351):13-20.

42. Teo K, For the ACE Inhibitors Collaborative Group, et al. Effects of long-term treatment with angiotensin-converting enzyme inhibitors in the presence or absence of aspirin: a systematic review. Lancet. 2002;360(9339):1037-43.

43. Freemantle $\mathrm{N}$, et al. $\beta$ Blockade after myocardial infarction: systematic review and meta regression analysis. BMJ. 1999;318(7200):1730-7.

44. Baigent C, Cholesterol Treatment Trialists'(CTT) Collaborators, et al. Efficacy and safety of cholesterol-lowering treatment: prospective metaanalysis of data from 90,056 participants in 14 randomised trials of statins. Lancet. 2005;366(9493):1267-78.

45. Rashid P, Leonardi-Bee J, Bath P. Blood pressure reduction and secondary prevention of stroke and other vascular events a systematic review. Stroke. 2003;34(11):2741-8.

46. Furberg C, The ALLHAT Officers and Coordinators for the ALLHAT Collaborative Research Group, et al. Major outcomes in high-risk hypertensive patients randomized to angiotensinconverting enzyme inhibitor or calcium channel blocker vs diuretic. The antihypertensive and lipid-lowering treatment to prevent heart attack trial (ALLHAT). JAMA. 2002;288:2981-97.

47. Eagle KA, et al. Adherence to evidence-based therapies after discharge for acute coronary syndromes: an ongoing prospective, observational study. Am J Med. 2004;117(2):73-81.

48. Gislason $\mathrm{GH}$, et al. Long-term compliance with beta-blockers, angiotensin-converting enzyme inhibitors, and statins after acute myocardial infarction. Eur Heart J. 2006;27(10):1153-8.

49. Ho PM, Bryson CL, Rumsfeld JS. Medication adherence its importance in cardiovascular outcomes. Circulation. 2009;119(23):3028-35.

50. WHO. Cost-effetiveness and strategic planning (WHO-CHOICE). 2005. http://www.who.int/choice/costs/CER_thresholds/en/. Accessed 03 Sept 2015.

51. United Nations, P.D., Population estimates and projections section. World Population Prospects: The 2012 revision. 2012. http://www.esa.un.org/ unpd/wpp/Excel-Data/population.htm. Accessed 28 Mar 2015.

52. Mathers C, Fat DM, Boerma J. The global burden of disease: 2004 update. Geneva: World Health Organization; 2008.

53. Salomon JA, et al. Common values in assessing health outcomes from disease and injury: disability weights measurement study for the Global Burden of Disease Study 2010. Lancet. 2013;380(9859):2129-43.

54. Murray CJ, et al. Disability-adjusted life years (DALYS) for 291 diseases and injuries in 21 regions, 1990-2010: a systematic analysis for the Global Burden of Disease Study 2010. Lancet. 2013;380(9859):2197-223.

55. Lauer JA, et al. PopMod: a longitudinal population model with two interacting disease states. Cost Eff Resour Alloc. 2003;1(1):6.

56. WHO. Cost-effectiveness and strategic planning: table: price of other (recurrent) tradable goods. 2014. http://www.who.int/choice/cost-effectiveness/inputs/tradable_goods/en/. Accessed 20 Mar 2014.

57. MSH. International drug price indicator guide. 2013. http://www.erc.msh org/dmpguide/index.cfm?search_cat=yes\&display=yes\&module $=\mathrm{dmp}$ \&language=english\&year=2013. Accessed 28 Mar 2015.

58. Baltussen RM, et al. Uncertainty in cost-effectiveness analysis. Int J Technol Assess Health Care. 2002;18(01):112-9. 
59. Berry JD, et al. Lifetime risks of cardiovascular disease. N Engl J Med. 2012;366(4):321-9.

60. Rapsomaniki E, et al. Blood pressure and incidence of twelve cardiovascular diseases: lifetime risks, healthy life-years lost, and age-specific associations in 1.25 million people. Lancet. 2014;383(9932):1899.

61. Jamison DT, et al. Disease control priorities in developing countries. Washington: World Bank Publications; 2006.

62. Boersma E, Simoons M. Reperfusion strategies in acute myocardial infarction. Eur Heart J. 1997;18(11):1703-11.

63. Revill P, et al. Using cost-effectiveness thresholds to determine value for money in low-and middle-income country healthcare systems: are current international norms fit for purpose? Center for Health Economics Reasearch Paper 98. The University of York; 2014.

64. Woods B, et al. Country-level cost-effectiveness thresholds: initial estimates and the need for further research. Center for Health Economics Research Paper 109. The University of York; 2015.

65. Norheim OF, et al. Guidance on priority setting in health care (GPSHealth): the inclusion of equity criteria not captured by cost-effectiveness analysis. Cost Eff Resour Alloc. 2014;12(1):18.
66. Baigent $C$, et al. Aspirin in the primary and secondary prevention of vascular disease: collaborative meta-analysis of individual participant data from randomised trials. Lancet. 2009;373(9678):1849-60.

67. Trialists CT. Efficacy and safety of more intensive lowering of LDL cholesterol: a meta-analysis of data from 170,000 participants in 26 randomised trials. Lancet. 2010;376(9753):1670-81.

68. Wright JM, Musini VM. First-line drugs for hypertension. New York: The Cochrane Library; 2009.

69. WHO. Cost-effectiveness and strategic planning. 2000. http://www.who. int/choice/interventions/rf_cvd/en/. Accessed 20 Jan 2014.

\section{Submit your next manuscript to BioMed Central and we will help you at every step:}

- We accept pre-submission inquiries

- Our selector tool helps you to find the most relevant journal

- We provide round the clock customer support

- Convenient online submission

- Thorough peer review

- Inclusion in PubMed and all major indexing services

- Maximum visibility for your research

Submit your manuscript at www.biomedcentral com/submit 